\title{
LEITURA DE POESIA E INTELIGÊNCIA EMOCIONAL: UMA DISCUSSÃO
}

Valmir Luis Saldanha da SILVA

\begin{abstract}
RESUMO
O presente artigo tem a função de abordar alguns modos como o texto poético pode atuar no processo de conhecimento de si, do outro e do mundo, além de investigar a ideia de que a leitura desse tipo de texto pode auxiliar no processo de criação e manutenção de identidades, tal qual se lê em Candido (1995) e Paz (2012). Para isso, baseamo-nos em poemas do italiano Luigi Pirandello (1991) e tomamos como ponto de partida a junção de inteligência emocional com a leitura de poemas. Concluímos defendendo que a poesia é fundamental para o desenvolvimento da imaginação humana.
\end{abstract}

PALAVRAS-CHAVE: poesia; inteligência emocional; criatividade; flexibilidade cognitiva; Luigi Pirandello.

\section{POETRY READING AND EMOTIONAL INTELLIGENCE: A DISCUSSION}

\section{ABSTRACT}

This paper has the function to discuss some ways in which the poetic text can do in the process of knowing oneself, the other and the world. It also investigates the idea that reading this type of text can assist in the process of creation and maintenance of identities, as read in Candido (1995) and Paz (2012). For this, we use the reading of Italian Luigi Pirandello's poetic texts (1991) and take as a starting point a union of emotional intelligence with poetic texts. We conclude that poetry is fundamental to the development of the human imagination.

KEYWORDS: poetry; emotional intelligence; creativity; cognitive flexibility; Luigi Pirandello.

\section{LETTURA DI POESIA E CREATIVITÀ: UNA DISCUSSIONE}

\section{RIASSUNTO}

Il presente articolo ha la funzione di discutere alcuni modi in cui il testo poetico può agire nel processo di conoscenza di se stesso, dell'altro e del mondo. Indaga anche sull'idea che la lettura di questo tipo di testo possa aiutare nel processo di creazione e mantenimento dell'identità, come letto in Candido (1995) e Paz (2012). Per questo, usiamo la lettura dei testi poetici di Luigi Pirandello (1991) e prendiamo come punto di partenza l'unione dell'intelligenza emotiva con $i$ testi poetici. Concludiamo sostenendo che la poesia è fondamentale per lo sviluppo dell'immaginazione umana.

PAROLE CHIAVE: poesia; intelligenza emotiva; creatività; flessibilità cognitiva; Luigi Pirandello.
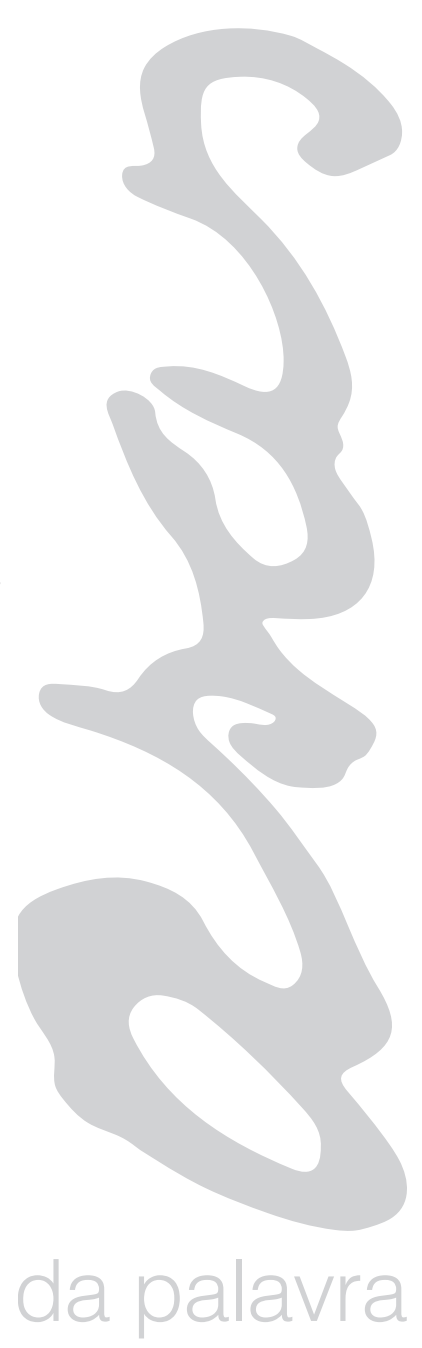

VOL.16|N.2|DEZ.2019 ISSN 1415-7950 


\section{INTRODUÇÃO}

O mundo contemporâneo vem mudando as habilidades esperadas dos profissionais para ingresso no mercado de trabalho. O profissional do século XXI deve ser capaz de trabalhar em rede - on-line e off-lineser capaz de variar de um bom relacionamento interpessoal para metas e objetivos pessoais sólidos, ser criativo e inovador, mas, principalmente, deve ter a capacidade de continuar aprendendo e de reinventar-se constantemente.

Neste artigo, através da redescoberta da escrita poética de Luigi Pirandello (1867-1936), conforme analisam Silva (2016) e Bosi (2016), propomos demonstrar algumas potencialidades da leitura poética em uma associação com o polêmico (WOYCIEKOSKI; HUTZ, 2009) tema da inteligência emocional (MAYER; SALOVEY, 1997) e com elementos correlatos a esse modelo de inteligência, como a criatividade e a flexibilidade cognitiva. Em suma, o presente artigo pretende demonstrar que a leitura de poesia pode auxiliar no entendimento que os sujeitos têm de si, dos outros e do mundo e que essas habilidades podem auxiliar em questões práticas, como a empregabilidade no mundo contemporâneo através do desenvolvimento da imaginação.

Em outras palavras,

Compreender a mensagem, compreenderse na mensagem, compreender-se pela mensagem - eis aí os três propósitos fundamentais da leitura, que em muito ultrapassam quaisquer aspectos utilitaristas, ou meramente "livrescos", da comunicação leitor-texto. Ler é, em última instância, não só uma ponte para a tomada de consciência, mas também um modo de existir no qual o indivíduo compreende e interpreta a expressão registrada pela escrita e passa a compreender-se no mundo. (SILVA, 2011, p. 51 - aspas do autor)

Se este é o sentido de leitura que assumimos, convém compreender a partir de qual viés percebemos o conceito de inteligência emocional. Com a publicação de Emotional Intelligence, de Daniel Goleman (1996), a ideia de inteligência emocional ganhou notoriedade nos mais diversos meios, principalmente na televisão, nos jornais e na mídia não especializada (WOYCIEKOSKI; HUTZ, 2009). Tal popularização fez com que John Mayer e Peter Salovey (1997), os 
mais científicos do termo. Assim, para os autores, a inteligência emocional é

a capacidade de perceber, analisar e expressar emoções, bem como de produzir emoções que auxiliam o pensamento; é, ainda, a habilidade de entender emoções, obtendo conhecimento emocional e, também, a capacidade de refletir sobre emoções e controlá-las para promover o crescimento emocional e intelectual (MAYER; SALOVEY, 1997, p.5 - tradução nossa)

Como se vê, tanto inteligência emocional quanto leitura, enquanto conceitos, revelam a necessidade de os sujeitos refletirem sobre os objetos com os quais interagem, a fim de constituíremse verdadeiramente como sujeitos. Essa constituição do ser na contemporaneidade, no entanto, passa quase que necessariamente pela questão do trabalho. Façamos, então, um paralelo entre economia e poesia.

\section{ECONOMIA E POESIA}

Em um primeiro momento, pode parecer absurdo fazer uma relação entre textos poéticos e questões socioeconômicas, todavia um olhar mais apurado revela que é possível tal associação. Vejamos, a título de exemplo, um quadro comparativo derivado de pesquisas do Fórum Econômico Mundial (2018, p.1-32), em que são apontadas, por ordem de relevância, as habilidades capazes de aumentar as chances de empregabilidade para a força de trabalho nos anos de 2015 e de 2022:

Tabela 1: As dez habilidades para a empregabilidade

\begin{tabular}{|c|c|}
\hline 2015 & 2022 \\
\hline 1. Solução de problemas complexos & 1. Pensamento analítico e inovação \\
\hline 2. Relacionamento interpessoal & 2. Aprendizagem ativa e de estratégias \\
\hline 3. Gestão de pessoas & 3. Criatividade, originalidade e iniciativa \\
\hline 4. Pensamento crítico & 4. Design tecnológico e programação \\
\hline 5. Negociação & 5. Pensamento crítico-analítico \\
\hline 6. Controle de qualidade & 6. Solução de problemas complexos \\
\hline 7. Orientação de serviço & 7. Liderança e influência social \\
\hline 8. Julgamento e tomada de decisão & 8. Inteligência emocional \\
\hline 9. Escuta ativa & 9. Flexibilidade cognitiva e concepção de ideias \\
\hline 10. Criatividade & 10. Análise e avaliação de sistemas \\
\hline
\end{tabular}

Future of Jobs Report. World Economic Forum. Disponível em: <https://www.weforum.org/ agenda/2016/01/the-10-skills-you-need-to-thrive-in-the-fourth-industrial-revolution/>. 
Dos itens apresentados, tomando os elementos de 2022 como base, quatro certamente têm uma relação direta com o trabalho que pode ser desenvolvido através dos textos poéticos, a saber: criatividade, originalidade e iniciativa (3), por meio do encontro de soluções diferentes para diversas situações problemáticas; liderança e influência social (7) em conjunto com inteligência emocional (8), por meio da gestão das emoções pessoais e da gestão dos confrontos externos; e flexibilidade cognitiva e concepção de ideias (9), por meio da capacidade de ousar e combinar elementos de diferentes maneiras. Mesmo que o senso comum acredite que o desenvolvimento das nações seja pautado exclusivamente por profissionais das áreas de Ciência, Tecnologia, Engenharia e Matemática, a execução de tais habilidades exige um estofo advindo das ciências humanas e da linguagem, pois determina que os sujeitos sejam capazes de organizar e relacionar pessoas, processos e objetivos de forma ética e responsável, bem como comunicar ideias com qualidade estética e eficiência.

Entendendo melhor, isso quer dizer que uma economia ou um Estado que se volte unicamente para o fator financeiro - ignorando que os números resultantes precisam ser produzidos, de um lado, e consumidos, de outro, por pessoas - tende a perder não as habilidades apontadas pelo Fórum Econômico, mas a relevância. A poesia, no entanto, pode ter um papel fundamental nesse contexto, pois tem o potencial de criar pontes para dentro dos sujeitos e combater a razão instrumental que o tecnicismo produz. Nesse sentido, a poesia atua como resistência, principalmente por colocar-se como um contraponto às pressões sociais e abordar o mal de viver instaurado pelo "industrialismo [que] coisifica as almas" (ADORNO; HORKHEIMER, 1991, p.40), mesmo fazendo desse mal o motor da própria vida.

No poema Exame, publicado na revista Roma letteraria (n. 19), em outubro de 1895, Pirandello aborda a dubiedade da vida que é, para este autor, mediada por máscaras sociais que escondem o que somos e revelam apenas o que parecemos ser:

\section{Exame}

Concretize, expresse seu desejo: o que você quer? - Nada! - Mas a paz ainda lhe falta...

Por que você não tem paz? - A alma está cansada! Cansada de quê? do que você pode sofrer? 
indagar; mas produzir, viver. Sonha

com outros remédios a sua mente? É tarde,

é tarde, e vão! Você não vai se recuperar.

$[\ldots]$

Salve, se puder, alguém! Ajude! Ajude

Procura um objetivo? Agora este é o seu objetivo!

Cesse suas perguntas inúteis: - E depois? -

Pereça com eles, e cale a investigação...

(PIRANDELLO, 1991, p.379 - tradução nossa).

Sistematizando a leitura deste poema, vemos uma espécie de confronto ideológico entre aquele que possui a "alma cansada" e que, por isso, não deseja mais "nada" e aquele que acredita que todo o "questionamento" em relação à vida é "vão", o que faz com que tenhamos que calar nossas investigações e, sem fugir às contingências de existir, perecer como todas as outras pessoas. Aqui, a tomada de consciência e o conhecimento emocional repousam no fato de se reconhecer a necessidade de se construir máscaras sociais para viver.

Se isso é inescapável, então a inteligência emocional que pode ser construída pela leitura do poema indica que tais máscaras devem relacionar-se ao menos à ilusão de salvar alguém, fazendo com que este seja o objetivo da própria existência. Assim, se o ceticismo é o caminho escolhido, não há porque continuar a questionar sem que isso traga uma ação verdadeira. Ou como literalmente a voz poética enuncia: "você não vive - olha a vida, e questiona: eis aí o seu mal!”. A mensagem do poema, portanto, se bem compreendida, pode fazer os sujeitos repensarem a si mesmos, bem como o lugar que ocupam dentro da estrutura social, o que poderia resultar, em última instância, em um alargamento da inteligência emocional e da flexibilidade cognitiva. Isso porque a interpretação poética, do modo como a construímos, revela tanto o plano da ficção quanto possibilita a construção do real (REDDAN; WAGER; SCHILLER, 2018).

É óbvio que alguém poderia trazer uma objeção, dizendo que a relação que este artigo propõe visa a um esvaziamento do caráter literário do texto poético, já que se espera que a poesia sirva apenas de forma instrumental para elevar a capacidade de adaptação das pessoas a novas condições de trabalho, como as expostas pelo Fórum Econômico Mundial. No entanto, cabe ressaltar que não se propõe tal ideia, pois não se espera que a poesia tenha esse caráter, 
ou que os escritores e as escritoras escrevam com esse intuito, mas, sim, que os leitores e as leitoras sejam capazes, se assim o desejarem, de compreender a experiência estética da poesia também como uma experiência profissional. Em outras palavras, se o mundo necessita de pessoas afins às habilidades citadas anteriormente, ele não pode ignorar o valor da poesia, uma vez que ela pode proporcionar uma experiência quase total de vida, pois "Em cada poema lírico devem ser encontrados [...] os sedimentos da relação histórica do sujeito com a objetividade, do indivíduo com a sociedade" (ADORNO, 2003, p. 72).

\section{QUEM É VOCÊ? QUEM SOU EU?}

O desenvolvimento da inteligência emocional depende, dentre outros fatores, de uma capacidade paradoxal: a introspecção. Apesar de ser vista com certa reserva dentro de sociedades pautadas pela exposição de imagens pessoais - tome-se, como exemplo, o advento das redes sociais, a importância dada à aparência e a prevalência social da retórica esvaziada sobre a lógica mais ordenada (CORTELLA; DIMENSTEIN, 2015) -, a introspecção é fundamental para que os indivíduos compreendam seus limites e consigam entender-se como sujeitos que convivem com outros sujeitos. Nesse sentido, a poesia, em sua dimensão mais ampla, pode auxiliar tanto no trabalho de leitura silenciosa, constituindo a identidade introspectiva do sujeito consigo mesmo, quanto no trabalho de leitura declamativa, auxiliando na alteridade expressiva dos sujeitos entre si, quer seja dentro de um grupo homogêneo ou de um heterogêneo.

O trabalho com a leitura poética, então, alinha-se à capacidade de compreensão emocional que, de acordo com Mayer, Salovey e Caruso $(2002,2004)$, relaciona-se a três habilidades que organizamos da seguinte maneira: a) a capacidade de identificar emoções e codificálas; b) a capacidade de entender os significados e o modo como as emoções constituem-se e correlacionam-se; e c) a capacidade de conhecer as causas e os efeitos das emoções. Pode-se argumentar que tais capacidades dependem muito mais do fator personalidade e que isso é algo inerente a cada sujeito, entretanto, pesquisas teórico-empíricas, como a realizada por Côbero, Primi e Muniz (2006), concluíram que

o construto de inteligência emocional parece ser um tipo específico de inteligência, que antes não 
a medidas tradicionais de inteligência podendo ainda ser útil na previsão do desempenho profissional. (CÔBERO, PRIMI, MUNIZ, 2006, p.346)

Como se vê, há comprovações científicas de que a inteligência emocional não é uma questão de personalidade apenas e, ainda, de que ela é útil na previsão do desempenho profissional dos sujeitos no mercado de trabalho, o que corrobora a conclusão do trabalho do Fórum Econômico Mundial. Sendo assim, é urgente que percebamos como a linguagem, em geral, e a linguagem poética, em específico, são capazes de construir, dissolver e/ou manter identidades. Claro que já há uma relevante e vasta literatura acadêmica sobre este último tema, mas normalmente esses estudos são sobre narrativas ou, então, estritamente psicológicos, psicanalíticos, sociológicos e antropológicos. Queremos partir desse conhecimento já construído e chamar a atenção para alguns autores que contribuíram nessas áreas do conhecimento para o entendimento das noções de "ser" e de "outro", bem como a correlação desses elementos com a noção de "mundo", a fim de definir melhor nosso objeto através do texto poético.

O filósofo e matemático Edmund Husserl (1965), por exemplo, em seus princípios fenomenológicos, entende o outro como um outro eu, isto é, um $t u$ com o qual o meu eu mantém contato. $\mathrm{Ou}$ seja, em Husserl, "tudo o que vale para mim vale também para todos os outros homens, que me estão à mão no meu mundo circundante. Experimentando-os como homens, compreendo-os e os aceito como 'eu', qual eu sou." (HUSSERL, 1965, p.61). Dessa forma, Husserl nos ajuda a perceber que as noções de outro e de mundo passam, necessariamente, pela experiência de reconhecer a si mesmo, já que o outro depende da visão que o eu tem sobre ele.

Por intermédio da linguagem corre o pensamento do filósofo, psicanalista e crítico literário Paul Ricoeur (1991) que, por meio das definições de identidade e ipseidade, vai tentar compreender a relação existente entre a teoria narrativa e a hermenêutica do si. Para ele "a compreensão do si é uma interpretação; a interpretação de si, por sua vez, encontra na narrativa, entre outros símbolos e signos, uma mediação privilegiada" (RICOEUR, 1991, p.138). Dessa forma, como sua análise remonta à narrativa, afirma que "a literatura é um vasto laboratório onde são testadas estimações, avaliações, julgamentos de aprovação e de condenação pelos quais a narrativa 
serve de propedêutica à ética" (RICOEUR, 1991, p.140).

Em outras palavras, a necessidade de estarmos em "permanente diálogo, explícito ou implícito, com o Outro é uma realidade cada vezmais intensa na cultura contemporânea, caracterizada pela heterogeneidade e simultaneidade de apelos vindos das mais variadas fontes. [...]" (DIAS; PITERI, 2010, p.7). Assim, para se compreender as habilidades exigidas pelo mundo do trabalho em consonância com uma análise da literatura, mais especificamente da poesia, teremos de vislumbrar uma espécie de resposta a alguns anseios de parte da sociedade estabelecida. Como bem já apontou o professor Antonio Candido, em seu ensaio $O$ direito à literatura:

Por isso é que nas nossas sociedades a literatura tem sido um instrumento poderoso de instrução e de educação, entrando nos currículos, sendo proposta a cada um como equipamento intelectual e afetivo [...] Ela [a literatura] não corrompe nem edifica, portanto; mas [...] humaniza porque faz viver. (1995, p. 243)

Partindo do que afirma Candido, a dimensão estética do conhecimento de si e do outro, fundamental para a criatividade, e a dimensão ética norteada pelas respostas às questões mais prementes da sociedade, passa por aquilo que entendemos como mal de viver (SILVA, 2016, p.67-73). Tal conceito abarca essas mesmas dimensões ética e estética, construídas ao longo de uma formação contextualizada pela dor, pelo medo, pela angústia, pelo sentimento do nada e pelo descaso do mundo.

Do nosso ponto de vista, a compreensão de que estamos envoltos por esse mal pode ser justamente o fator de impulso para a invenção de novidades que melhorem a existência. Ou seja, recordarse de que somos seres finitos, cuja vida fatalmente será extinta, deve dialeticamente construir uma inteligência emocional mais plena e, por conseguinte, apontar para a necessidade de buscar a vida que vale a pena ser vivida. No poema $O$ último café, de Pirandello, temos um exemplo do que afirmamos: 
que a estrutura

vital se descombina.

$[\ldots]$

(Avizinha-se

a morte

de quem não pode dormir.)

Debruçado sobre o fogo

sopra forte o velhinho;

depois a caneca branca

habitual

prepara: três torrões

de açúcar, porque para ele

o café tem sempre sabor amargo.

O fogo levanta faíscas.

(Velhinho amigo,

você talvez não me espere.

Mas em breve

Você virá comigo.)

[‥]

Ainda, ainda um gole,

velhinho, não dê ouvidos

Porque você olha ao redor?

Silêncio. Tocam os sinos.

Cinco horas. Quem você espera?

É dia, percebe? é dia

já claro.

Termine o seu café.

(Depois, velhinho amigo, anime-se!, você virá comigo.)

(PIRANDELLO, 1991, p. 421-424 tradução nossa).

Esse poema, publicado na revista Riviera Ligure (n. 6) de 1912, revela o olhar de quem analisa a vida como um caminho sem volta para a morte, no entanto, sem grandes afetações ou dramas. É como se ele apontasse para o fato de que antes de poder responder à questão Quem eu sou? tivéssemos de responder à questão Como me torno (ou me tornei) quem sou? Essa intensa travessia existencial, essa condição de ser humano perdido e sem identidade própria é que se deve entender como o ponto de inflexão do mal de viver, que nada mais é do que uma intuição bastante precisa, beirando à conceituação 
filosófica, sobre o problema da existência humana.

Do ponto de vista da leitura, a inteligência emocional e a flexibilidade cognitiva são possíveis efeitos do entendimento mais completo de um poema como este, pois vimos como a existência humana, apesar de não ter significado aparente, constrói o seu viver em simbiose com o mal de viver. Para além disso, tal trabalho poético incita a imaginação e impõe que cada leitor coloque-se no lugar do "velhinho" e seja capaz de associar-se a uma vida que não é a sua própria como única alternativa possível para compreensão ideológica do conteúdo poético.

Assim, a construção e a manutenção das identidades, quando as analisamos pelo viés poético, ultrapassam os limites já acordados entre os seres e pedem criatividade para que cada sujeito seja capaz de encontrar seu lugar no mundo. Tomemos as palavras de Octávio Paz, no capítulo $A$ revelação poética de seu $O$ arco e a lira, como base:

A ausência de significação decorre do fato de
que o homem, sendo quem dá sentido às coisas e
ao mundo, de chofre percebe que não tem outro
sentido senão morrer. A experiência da queda no
caos é indizível: não podemos dizer nada sobre nós,
nada sobre o mundo, porque nada somos. Mas, se
nomeamos o nada - como efetivamente fazemos -,
este se ilumina com a luz do ser. Pois da mesma
maneira: viver diante da morte é inseri-la na vida.
[...].
No entanto, em todos esses estados há uma espécie
de maré rítmica: a revelação da insignificância
que é o homem se transforma na revelação do seu
ser. Morrer, viver: vivendo morremos, morremos
vivendo. (PAZ, 2012, p.158-159)

A relação entre o olhar de Octávio Paz e o poema de Luigi Pirandello encontra-se no fato de que, em tese, não podemos dizer nada sobre nós e nada sobre o mundo, mas o fazemos mesmo assim. E essa resistência ao nada e à morte que a poesia condensa em si mesma é que parece ser capaz de fomentar a inteligência emocional, aumentando a capacidade humana de gerenciar as próprias emoções e atuar nos processos de formação do eu e de consolidação do outro e do mundo.

Nesse sentido, a catarsis que a leitura poética pode provocar (HAMBURGER, 1986), quando trabalhada com essa intenção, acaba tendo um viés cidadão na percepção e na construção de sensibilidade, 
REVISTA DO PROGRAMA DE PÓS-GRADUAÇÃO EM COMUNICAÇÃO, LINGUAGENS E CULTURA DA UNIVERSIDADE DA AMAZÔNIA

interpessoais, sob pena de exclusão social daqueles que não atingem os patamares desejáveis dessas habilidades, conforme estamos apontando.

É justamente por isso que os poemas de Pirandello que aqui elencamos funcionam como exemplos empíricos de funcionalidades práticas relacionadas ao trato poético, ampliando as possibilidades interpretativas do mundo, do eu e do outro. A poética de Pirandello, como é notório, não combate o mundo, mas o revela aos olhos de quem não o vê, pois, como poesia, "afirma que a vida humana não se reduz ao 'preparar-se para morrer' de Montaigne, nem o homem se reduz ao 'ser para a morte' da análise existencial. A existência humana encerra uma possibilidade de transcender a nossa condição." (PAZ, 2012, p. 162).

\section{ENCONTRAR(-SE N)A LINGUAGEM}

Entender-se e comunicar, para si e para os outros, são fatores linguísticos. Com efeito, se questões práticas como empregabilidade no mundo contemporâneo dependem cada vez mais de criatividade, flexibilidade cognitiva, influência social e inteligência emocional, então também é necessário que cada vez mais sejam trabalhadas habilidades relacionadas aos mais diferentes usos das línguas e das linguagens. Isso porque "palavras são nossas ferramentas [...]. [E] nós estamos usando uma consciência aperfeiçoada das palavras para aprimorar nossa percepção [...] dos fenômenos" (AUSTIN, 1970, p.182-183 - tradução nossa).

No desenvolvimento dessas habilidades por meio da estética do poema, portanto, teremos de perceber como a linguagem auxilia, enquanto fator de cultura, na construção das identidades e como isso é relevante para entendermos certa "função social” da poesia. Neste caso, a linguagem poética auxilia na construção da inteligência emocional de "perceber, analisar e expressar emoções" (MAYER; SALOVEY, 1997, p.5), por estruturar-se na inter-relação entre os componentes do discurso, ou seja, na capacidade que os interlocutores têm de interpretar os elementos de linguagem, os signos (PEIRCE, 1977), e os transformar em conteúdo apreensível. Daí entendermos que “A linguagem, portanto, é um sistema de representações aceitas por um grupo social, que possibilita a comunicação entre os integrantes desse mesmo grupo." (ARANHA, 2003, p. 31). 
Esses fatores servem para que identifiquemos a existência de uma distinção entre língua e linguagem, enquanto estrutura, mas também, o funcionamento delas como partes de um mesmo fundamento na tentativa de determinação dos sujeitos como seres de cultura e, por isso mesmo, na distinção das próprias culturas: “A linguagem, portanto, é produto da razão e só pode existir onde há racionalidade." (ARANHA, 2003, p.31). Por isso, o ato de nomearmos os itens que nos cercam, por exemplo, já é um ato cultural, pois há uma ponte entre a representação linguística e o objeto representado que se dá de maneira arbitrária, mas que, ao mesmo tempo, uma vez constituída como tal, passa a ser parte integrante dessa mesma cultura.

Assim, os repertórios de uma língua condicionam as linguagens possíveis e, como consequência, influenciam o modo como se compreende a realidade. Isso quer dizer que a realidade é captada e transmitida pela linguagem. Como afirma Schaff:

A compreensão dos signos, a compreensão
da linguagem, é a base da comunicação. Para
compreender um signo temos de percebê-lo e ao
mesmo tempo experimentar um ato psíquico [...].
Em outras palavras, trata-se aqui de uma distinção
entre comunicação no sentido de transmissão de
significações de expressões e comunicação no
sentido de transmissão de convicções. Se, em
contradistinção com mal-entendidos, concordamos
em que esta comunicação é um processo de produção
de signos, por uma parte, e de percepção desses
signos, pela outra parte, acompanhado pela mesma
compreensão desses signos por ambas as partes,
então comunicação efetiva consiste nesse processo,
desde que, além disso, a mesma compreensão dos
signos seja acompanhada pelas mesmas convicções.
(1968, p.344-345 - grifos do autor).

Estando de acordo com esta definição, é possível afirmar que a nenhuma inteligência é facultada a possibilidade de criar uma realidade absolutamente zerada, isto é, os seres humanos não podem inventar um mundo completamente novo sem levar em consideração aquilo que seus sentidos já captaram e captam. Assim, é nossa capacidade de interpretação dos signos, ligada ao trabalho linguístico-formal do discurso e ao contexto histórico-social em que esse discurso circula, que nos permite criar uma identidade linguística que alicerça uma VOL. 16 | N.2 | DEZ.2019 identidade ontológica, isto é, uma identidade do ser. 
Essa aparente complicação na relação entre signo e ser desfazse rapidamente quando nos recordamos de que para se compreender o texto poético atuando no processo de conhecimento e de constituição da inteligência emocional é de suma importância passar pelo processo de compreensão dos signos poéticos e das relações que os leitores e as leitoras poderão tecer, a partir daí, para construir uma noção de si mesmos e de tudo que os cerca. Essa possibilidade de compreensão, portanto, poderá ser levada a efeito através dos elementos linguísticos constituintes do texto poético. Como afirma T. S. Eliot (1991), essa é a função social da poesia:

\begin{abstract}
A poesia está primeiramente ligada à expressão dos sentimentos e das emoções: e esse sentimento e emoção são particulares, ao passo que o pensamento é geral. [...]

Ao expressar o que os outros sentem, ele [o poeta] está também modificando o sentimento, tornando-o mais consciente: está fazendo com que as pessoas percebam melhor o que sentem, ensinando-lhes, portanto, algo a respeito de si mesmas. [...] E pode fazer com que seus leitores compartilhem conscientemente novas sensações ainda não vivenciadas. (ELIOT, 1991, p. 32-35 grifo nosso).
\end{abstract}

De acordo com os ensinamentos de Eliot, quando o poeta consegue transcrever "o que os outros sentem", ele consegue fazer com que as pessoas tornem-se "mais conscientes" e compreendam "algo a respeito de si mesmas". Ora, e não seria essa uma competência fundamental para fazer a gestão das emoções que nos envolvem e que tocam aqueles com quem convivemos? E, mais, não são esses mesmos fatores que contribuem de maneira decisiva para tomadas de decisão mais eficientes e, ao mesmo tempo, mais inovadoras? Como a resposta a essas perguntas é obviamente "sim", talvez seja essa uma chave no entendimento da poesia como elemento de atualização (reskilling) e aprimoramento (upskilling) das habilidades pessoais em um mundo altamente competitivo como o que se apresenta às novas gerações.

As ferramentas de observância da existência estão, em determinada medida, na própria crítica da poesia. Para o professor Antonio Candido (1995a, 1996), por exemplo, o poeta tem como objeto de trabalho a palavra, em suas dimensões de som, sentido e 
imagem. Para nós, o século XXI pede por pessoas que também consigam reconfigurar as noções de som, sentido e imagem nos mais diversos contextos. Esse é o fator de criatividade, influência social e inteligência emocional que se espera e que pode advir do convívio com os mais diferentes tipos de poema possíveis. Isso pelo fato de que ser capaz de compreender poemas é, também, ser capaz de associar os sons, os sentidos e as imagens poéticas àquilo que cada um de nós vive, viveu e é capaz de viver em si. Mas também ser capaz de perceber que o que nunca se viveu pode perfeitamente ser vivido por outro alguém, tal qual na leitura do "velhinho" do poema $O$ último café.

Tal capacidade cognitiva, que entendemos como o ponto de encontro entre a leitura poética e a inteligência emocional, só é possível de ser plenamente trabalhada e desenvolvida se conseguirmos compreender que "a linguagem pode ser usada não só para narrar ou descrever algo, mas também para realizar algo." (TERRA, 2014, p.20; AUSTIN, 1970).

\section{TÁTICA E PRÁTICA}

Quando Candido insere a literatura no rol das necessidades básicas humanas, tendo em vista que ela "confirma e nega, propõe e denuncia, apoia e combate, fornecendo a possibilidade de vivermos dialeticamente os problemas" (CANDIDO, 1995, p.243), ele demonstra que a modalidade linguístico-pragmática da ficção tem o poder de nos fazer viver e de nos fazer ver-nos - e aos outros - vivendo.

Dessa maneira, a fim de apontarmos para um modelo prático do que teoricamente apontamos, demonstremos uma leitura poética com o potencial de desenvolver a inteligência emocional. Tomemos como exemplo o poema Sempre animal, publicado no livro Fuori di chiave (1912) de Pirandello:

\section{Sempre animal}

Sem fazer nada, um leão é um leão: e um pobre homem deve enfrentar a morte para ter a honra de ser comparado com aquele animal que, sem esforço, é forte.

De grandes pensamentos a alma infeliz nutre-se, até que se eleva a excelsos lugares. Um grande prêmio lhe aguarda. Então se diz que verdadeiramente você é uma águia. 
a sua dor intensa e ardente, faça disso uma sublime poesia.

e lhe dirão que você é um rouxinol.

Mas, finalmente, para não ser um animal

o que deve fazer o homem? não fazer nada?

Não ter nem angústia nem irritação?

Se assim o fizer, de burro the chamarão.

(PIRANDELLO, 1991, p.233 - tradução nossa).

No poema em questão, seguindo os pressupostos de Candido (1995a, 1996) e Eliot (1991), ganham relevância o sentido e as imagens que as palavras possuem dentro do texto, enquanto o som fica em segundo plano. A análise poética revela que o eu lírico parece observar a natureza e tirar conclusões que dizem respeito ao ser e estar no mundo humano. Assim, a cada vez que um ser humano consegue ultrapassar a linha média dos mesmos de sua espécie, o senso comum já o compara a algum animal. Por conseguinte, o sujeito que enfrenta a morte é como um leão, aquele que eleva os tristes pensamentos a um lugar excelso é como uma águia, o que transforma a dor de viver em harmonia (o poeta) é como um rouxinol e, por fim, aquele que busca fugir das dores humanas nada mais é do que um burro. Em outras palavras, o poema nos faz constituir a inteligência emocional de perceber que o mal de viver é inerente ao próprio viver, resultante da oposição entre as forças da natureza e da razão.

O poema, então, contribui com nossa "capacidade de refletir sobre emoções e controlá-las para promover o crescimento emocional e intelectual" (MAYER; SALOVEY, 1997, p.5). Mas em que sentido isso acontece? A resposta é que ele o faz demonstrando a necessidade de se colocar em xeque a crença absoluta na racionalidade humana. $\mathrm{O}$ fator racionalidade, principal responsável pela distinção do animal ser humano dos outros animais, é também aquele que nos dá a consciência de nossa existência. Assim, o "leão", a "águia", o "rouxinol" ou mesmo o "burro", por exemplo, não possuem consciência e, por isso, são livres. O paradoxo, no entanto, é que essa liberdade não lhes permite escolher quais trajetórias desejam seguir, pois se movem fundamentalmente pelos instintos.

O trabalho de aprender os conteúdos emocionais, como se vê, depende da capacidade do leitor de perceber as imagens e as metáforas textuais, o que pode ser ensinado através de repetições e de leituras compartilhadas (REDDAN; WAGER; SCHILLER, 2018). Contudo, 
qualquer conteúdo que seja veiculado textualmente necessita de uma forma. Neste caso, bem relevante é a estruturação dos terceiros versos de cada estrofe, que contêm uma espécie de chave interpretativa do texto. Isso se dá pela irônica adjetivação que ocorre nas passagens "honra de ser comparado", "grande prêmio", e "sublime poesia". O ápice do "sentimento do contrário" (PIRANDELLO, 1999), no entanto, fica na última estrofe com a explicitação da necessidade de fugir dessa estranha honra de ser como os animais, que faz com que o ser humano não seja agente, mas sim, paciente em sua própria vida. Ou seja, não querer "ter nem angústia nem irritação", apesar de ser o caminho mais fácil, apenas demonstra covardia e incapacidade intelectual. A associação metafórica com o "burro", neste caso, esclarece a ironia, pois remete a um comportamento teimoso, bobo e ignorante: o típico comportamento humano quando este foge aos dilemas intrínsecos à existência.

É interessante notar o ponto de vista existencialista que escapa do poema, pois toda escolha humana sempre entra em conflito com o seu contrário, isto é, ao se escolher um caminho sempre há a possibilidade de se escolher outro qualquer, ou mesmo nenhum. "Com efeito, não há dos nossos atos um sequer que, ao criar o homem que desejamos ser, não crie ao mesmo tempo uma imagem do homem como julgamos que deve ser." (SARTRE, 1970, p.26). Por isso é que um dos aspectos da inteligência emocional que pode ser trabalhado em um poema como este é compreender que nossa existência não é algo individual, mas que tem desdobramentos em toda a humanidade. Isso demonstra que as escolhas individuais entram em conflito, necessariamente, com todas as escolhas das outras pessoas que habitam o mundo. Ter consciência dessa condição humana, desse aspecto da vida, é fundamental para desenvolver criatividade, originalidade e iniciativa; liderança e influência social; flexibilidade cognitiva e concepção de ideias; e inteligência emocional da forma mais segura possível.

No poema Sempre animal, a falta dessas habilidades é o motivo do julgamento de "burro". No caso, quando o ser humano desejar fugir de todas as tristezas, melancolias, irritações e "das particularidades, alegres ou tristes [...] pelas quais nós somos nós mesmos" (PIRANDELLO, 2002, p.264) perde de novo sua condição humana e passa a ser pejorativamente chamado de "burro" por aqueles que julgam sua ação. "Burro", nestes termos, é o ser que abdica das possibilidades de construir a própria existência, isto é, aquele que estando nu e podendo 
escolher tantas roupas quantas fossem possíveis escolheu apenas um tipo e, portanto, não compreendeu o jogo de máscaras sociais em que estamos inseridos ainda hoje. Nas palavras do próprio Pirandello, quando define o humorismo, “'O homem é um animal vestido [...]'. E o vestuário compõe também, compõe e esconde: duas coisas que o humorismo não pode suportar." (PIRANDELLO, 1999, p.176).

Enfim, como a leitura estrutural e semântica do poema demonstrou-nos, a inteligência emocional, com sua capacidade de regular emoções para promover o desenvolvimento e o bem-estar emocional e intelectual (MAYER; SALOVEY, 1997), impele-nos a existir resistindo ao mal de viver. A escrita pirandelliana, dessa forma, através do questionamento da esperança vã permite que dialeticamente seja construída uma visão analítica da própria vida. Esse procedimento de pensar a si mesmo e tentar compreender seu lugar no mundo é o que move cada um de nós a tentar encontrar respostas criativas aos problemas motivados pelas novas organizações sociais que se sucedem, mas também aos mesmos problemas que sempre afetaram a humanidade.

\section{CONSIDERAÇÕES FINAIS}

Por certo, a leitura de poemas como os de Pirandello, que aqui apresentamos, é uma leitura que se apoia nos opostos como forma de revelar o ser humano. Como já afirmamos, a poesia em geral não apenas combate o mundo, mas o revela aos olhos de quem não o vê. Com esses exemplos e essas discussões, esperamos ter demonstrado um caminho que pode - e deve - continuar a ser trilhado nas investigações acerca da poesia servindo como mediadora do entendimento da inteligência emocional como fundadora de uma concepção humana redimensionada dentro das exigências daquilo que a economia vem compreendendo como fundamento do mundo do trabalho.

Portanto, a capacidade de identificar emoções, decodificá-las, entender seus significados e conhecer suas causas e efeitos, atributos essenciais do que a ciência vem compreendendo como inteligência emocional, ganha um excelente aliado no poema, mais precisamente no trabalho de leitura de textos poéticos, que passam de inúteis adornos para linguagem que cria sujeitos. Uma sociedade em que as práticas inúteis, como as da poesia ou da filosofia, por exemplo, 
sejam valorizadas positivamente, terá oportunidades de estabelecer paradigmas que respeitem objetivos concretos, como os parâmetros definidos pelo Fórum Econômico Mundial, sem precisar fugir das abstrações fabuladoras.

Acreditamos fortemente que os elementos crítico-analíticos demonstrados neste artigo já são suficientes para que se possa repensar, ao menos em alguns aspectos, o papel da leitura de poesia dentro de sociedades marcadamente governadas pelo saber técnico-matemático. Não obstante, descobertas recentes da neurociência, como as divulgadas no artigo de Reddan, Wager e Schiller, Attenuating Neural Threat Expression with Imagination (2018), corroboram nosso ponto de vista e enfraquecem consideravelmente qualquer argumento cético. No artigo em questão, os autores comprovam a eficácia da imaginação, como realidade neurológica, na reorganização do cérebro, a fim de reverter ansiedades, fobias e medos profundos. Essa plasticidade cerebral medida usando ressonância magnética funcional (fMRI) -, capaz de modificar a estrutura da realidade dos sujeitos, foi conseguida através da capacidade de "aprender" e de "desaprender" através de mecanismos de percepção e associação (REDDAN; WAGER; SCHILLER, 2018, p.1001-1003), ou seja, através da imaginação. Para nós, uma das melhores formas de construir a capacidade imaginativa é, como buscamos demonstrar, justamente a leitura de poesia a partir dos sons, dos sentidos e das imagens que a constituem.

Assim, se almejamos uma sociedade em que as soluções para os problemas da existência sejam soluções efetivas e criativas, não podemos esperar que elas (as soluções) trilhem por caminhos já traçados, mas sim, que abram novas possibilidades, as quais, num primeiro momento, podem até soar absurdas, mas efetivamente contribuem para a flexibilidade cognitiva, o desenvolvimento da criatividade, a liderança e a influência social e, finalmente, a inteligência emocional. É desse fator que escapa o paradoxo da utilidade/ inutilidade, já que uma pressupõe a outra e qualquer delas que seja apagada implica a perda de ao menos metade das possibilidades de realização humana, o que, certamente, não é um valor positivo para a sociedade de mercado dentro da qual nos inserimos.

\section{REFERENCIAS}

ADORNO, Theodor W. Notas de Literatura I. Trad. Jorge M. B. de Andrade. São VOL. 16 | N.2 | DEZ. 2019 Paulo: Duas cidades; Ed. 34, 2003. 
ADORNO, Theodor W; HORKHEIMER, Max. Dialética do esclarecimento: fragmentos filosóficos. $2^{\mathrm{a}}$ ed. Rio de Janeiro: Zahar, 1991.

ARANHA, Maria Lúcia de A.; MARTINS, Maria Helena P. Filosofando: Introdução à filosofia. $3^{\mathrm{a}}$ ed. revista. São Paulo: Moderna, 2003.

AUSTIN, John L. Philosophical Papers. $2^{\text {a }}$ ed. Eds. J. O. Urmson and G. J. Warnock. London: Oxford University Press; Claredon Press, 1970.

BOSI, Alfredo. "A poesia de Pirandello". Revista de Letras, 56(2), 15-20, 2016. In: $<$ https://periodicos.fclar.unesp.br/letras/article/view/11371>. Acesso em: 05 de Novembro de 2019.

CORTEllA, Mário Sergio; DIMENSTEIN, Gilberto. A Era da Curadoria: o que importa é saber o que importa!: Educação e formação de pessoas em tempos velozes. Campinas, SP: Papirus 7 Mares, 2015.

CANDIDO, Antonio O estudo analítico do poema. São Paulo: Humanistas/ FFLCH/ USP, 1996.

O direito à literatura. In: Vários escritos. $3^{\mathrm{a}}$ ed. rev. e ampl. São Paulo: Duas Cidades, 1995. 1995a.

. Na sala de aula: caderno de análise literária. $5^{\mathrm{a}}$ ed. São Paulo: Ática,

DIAS, Maria Heloísa Martins; PITERI, Sônia Helena de Oliveira Raymundo (Org.). A literatura do Outro e os Outros da literatura. São Paulo: Cultura Acadêmica,

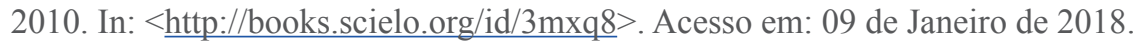

ELIOT, Thomas S. De poesia e de poetas. Trad. e prólogo Ivan Junqueira. São Paulo: Brasiliense, 1991. In: <https://prioste2015.files.wordpress.com/2015/04/ t12 eliot.pdf.> Acesso em: 09 de Janeiro de 2018.

WORLD ECONOMIC FORUM. "Preparing the future workforce". In: The Future of Jobs Report. Geneva: World Economic Forum, p.1-32, 2018. In: < http://www3. weforum.org/docs/WEF_Future of Jobs_2018.pdf $>$. Acesso em: 05 de Novembro de 2019.

GOLEMAN, Daniel. Inteligência emocional: a teoria revolucionária que redefine o que é ser inteligente. Trad. Marcos Santarrita. Rio de Janeiro: Objetiva, 1996.

GRAY, Alex. The 10 skills you need to thrive in the Fourth Industrial Revolution, 2016. In: <https://www.weforum.org/agenda/2016/01/the-10-skills-you-need-tothrive-in-the-fourth-industrial-revolution/> . Acesso em: 09 de Janeiro de 2018.

HUSSERL, Edmund. Idee per una fenomenologia pura e per una filosofia fenomenologica: Vol.1 Libro primo: Introduzione generale alla fenomenologia pura. Trad. Enrico Filippini. Torino: Einaudi, 1965.

MAYER, John D; SALOVEY, Peter. "What is emotional intelligence?". In: SALOVEY, Peter; SLUYTER, David D. (Eds.). Emotional development and emotional intelligence: Implications for educators. New York: Basic Books, p.331, 1997. In: http://ei.yale.edu/wp-content/uploads/2014/02/pub219 Mayer Salovey 1997.pdf. Acesso em: 28 de Outubro de 2019.

MAYER, John D., SALOVEY, Peter \& CARUSO, David R. (2002). MayerSalovey-Caruso Emotional Intelligence Test (MSCEIT) user's manual. Toronto, Canada: MHS.

MAYER, John D., SALOVEY, Peter \& CARUSO, David R. (2004). "A further consideration of the issues of emotional intelligence". Psychological Inquiry, 
15(3), p. 249-255. In: <http://ei.yale.edu/wp-content/uploads/2014/01/pub59 MayerSalovey2004_FurtherConsideration.pdf $>$. Acesso em: 05 de Novembro de 2019.

PAZ, Octavio. O Arco e a lira. Trad. Ari Roitman e Paulina Wacht. São Paulo: Cosac Naify, 2012.

PEIRCE, Charles S. Semiótica. São Paulo: Perspectiva, 1977.

PIRANDELLO, Luigi . O falecido Mattia Pascal; Seis personagens à procura de um autor. Trad. Fernando Correa Fonseca. São Paulo: Ed. Nova Cultural, 2002.

O humorismo. In: GUINSBURG, Jacó (Org.). Pirandello: do teatro no teatro. Trad. Jacó Guinsburg. São Paulo: Perspectiva, 1999. 1991.

Tutte le poesie. Introduzione di Francesco Nicolosi. Milano: Mondadori,

REDDAN, Marianne C.; WAGER, Tor D.; SCHILLER, Daniela. "Atenuation Neural Threat Expression with Imagination". Neuron, 100, p.994-1005, 2018. In: < http:// www.appliedmarianne.com/reddanetal2018.html $>$. Acesso em: 05 de Novembro de 2019.

RICOEUR, Paul. O si-mesmo como um outro. Trad. Luci Moreira Cesar. Campinas: Papirus, 1991.

SARTRE, Jean-Paul. O ser e o nada: ensaio de ontologia fenomenológica. Trad. Paulo Perdigão. 13 ed. Petrópolis/RJ: Vozes, 2005.

O existencialismo é um humanismo. Trad. e notas Vergílio Ferreira. $3^{\mathrm{a}}$ ed. Lisboa: Presença, 1970.

SCHAFF, Adam. Introdução à semântica. Rio de Janeiro: Civilização Brasileira, 1968.

SILVA, Valmir Luis Saldanha da. O mal de viver na poesia de Luigi Pirandello. 2016. 138f. Dissertação (Mestrado em Estudos Literários) - UNESP, FCLAr. Disponível em: http://repositorio.unesp.br/handle/11449/141530. Acesso em 01 de Novembro de 2019.

TERRA, Ernani. A leitura do texto literário. São Paulo: Contexto, 2014.

WOYCIEKOSKI, Carla; HUTZ, Claudio Simon. "Inteligência emocional: teoria, pesquisa, medida, aplicações e controvérsias". In: Psicologia: Reflexão e Crítica. 22(1), 2009. In: $<$ http://www.scielo.br/scielo.php?script=sci arttext\&pid=S010279722009000100002\#back $>$. Acesso em 01 de Novembro de 2019.

Recebido em 10 Set 2019 | Aprovado em 02 Nov 2019

Valmir Luis Saldanha da SILVA

Prof. de Língua Portuguesa do IFSP - Campos do Jordão, doutorando em Estudos Literários pela UNESP - Araraquara, membro do grupo de estudos LLE (Linguagem, Literatura e Educação) - IFSP. E-mail: professorvalmirluis@gmail.com; valmir.saldanha@ifsp.edu.br. 